\title{
RELACIONES ENTRE CORTES GENERALES Y GOBIERNO: SOBRE LA INVESTIDURA DEL PRESIDENTE DEL GOBIERNO $Y$ LOS MECANISMOS DE EXIGENCIA DE LA RESPONSABILIDAD POLÍTICA (1978-2016)
}

\author{
M. a ISABEL ÁLVAREZ VÉLEZ
}


SUMARIO

I. ENCUADRE DEL TEMA: LA IMPORTANCIA DE LAS RELACIONES GOBIERNO-CORTES GENERALES EN UN SISTEMA PARLAMENTARIO COMO EL DE LA CONSTITUCIÓN ESPAÑOLA DE 1978. II. EL PROCESO DE INVESTIDURA DEL PRESIDENTE DEL GOBIERNO A LO LARGO DE LAS DIFERENTES LEGISLATURAS. III. ACERCA DE LA EFICACIA DE LOS MECANISMOS DE EXIGENCIA DE LA RESPONSABILIDAD POLÍTICA: LA CUESTIÓN DE CONFIANZA Y LA MOCIÓN DE CENSURA. IV. A MODO DE RECAPITULACIÓN. 


\title{
RELACIONES ENTRE CORTES GENERALES Y GOBIERNO: SOBRE LA INVESTIDURA DEL PRESIDENTE DEL GOBIERNO Y LOS MECANISMOS DE EXIGENCIA DE LA RESPONSABILIDAD POLÍTICA (1978-2016)
}

\author{
M. ${ }^{\mathrm{a}}$ ISABEL ÁLVAREZ VÉLEZ ${ }^{1}$ \\ Profesora Propia Ordinaria de Derecho Constitucional \\ Facultad de Derecho (ICADE) \\ Universidad Pontificia Comillas
}

\author{
I. ENCUADRE DEL TEMA: LA IMPORTANCIA DE LAS \\ RELACIONES GOBIERNO-CORTES GENERALES EN UN \\ SISTEMA PARLAMENTARIO COMO EL DE LA CONSTITUCIÓN \\ ESPAÑOLA DE 1978
}

\begin{abstract}
Este trabajo forma parte de mi contribución al merecido homenaje por el XL aniversario de la elaboración y aprobación de la Constitución Española de 1978. Es preciso comenzar señalando que, desde la entrada en vigor de la Constitución, España ha vivido momentos de grandes beneficios, políticos, sociales, culturales e incluso económicos, aunque también se han vivido momentos difíciles. Nuestra Constitución se ha convertido ya en el segundo texto de más larga vigencia en nuestra historia contemporánea, sólo superada por la Constitución de 1876, válida durante cuarenta y siete años, aunque en una situación jurídico-política imposible de comparar con la que hemos vivido nosotros.
\end{abstract}

${ }^{1}$ M. Isabel Álvarez Vélez. Profesora Propia Ordinaria de Derecho Constitucional. Universidad Pontificia de Comillas (ICADE). Calle Alberto Aguilera, 23 - 28015 Madrid. Email: mba@comillas.edu 
La elaboración de la Constitución de 1978 duró quince meses, entre agosto de 1976 y octubre de 1977, y en su redacción se emplearon más de cuatrocientas horas de debates parlamentarios. Pero estos datos poco aportan, si no se hace referencia a la voluntad unánime de sus artífices de lograr un entendimiento que pusiera fin a un largo período de ruptura. Ciertamente, el texto se caracteriza por el consenso político de los grupos parlamentarios, de modo que no se trata de la obra de un partido, sino del conjunto de las fuerzas políticas. Esto ha dado lugar a que la Constitución no siga un único modelo, sino que ha adoptado diferentes tendencias, uniendo elementos de distintas ideologías y estableciendo principios políticos, si no originales, sí escogidos como medios para conseguir los fines propuestos.

La España del siglo XIX se caracterizó por tener una amalgama de textos constitucionales enmarcados en una situación de inquietud y alarma, de lucha en definitiva, de las diferentes posiciones que intentan imponer sus ideas, defendiendo a la vez los textos constitucionales que las recogen ${ }^{2}$. Igualmente, los inicios del siglo xx supusieron uno de los momentos más tristes y difíciles de nuestra historia reciente. Desde 1978 España ha sido modelo de significativos cambios y se han dado muestras de prudencia y audacia, a la vez. Y se celebra este importante aniversario en un momento en el que también la situación política es convulsa, no sólo por los problemas de carácter territorial que estamos teniendo, sino también porque es la primera vez que un Gobierno está siendo apoyado por una mayoría parlamentaria ciertamente endeble, casi podríamos decir inestable.

Desde la aprobación de la Constitución de 1978 hemos tenido varios Presidentes del Gobierno que han necesitado de apoyos parlamentarios de otros partidos para poder obtener la investidura, pero esta situación se agravó especialmente en 2016 cuando el Congreso de los Diputados no consiguió llegar a un acuerdo para otorgar su confianza al candidato propuesto por el Rey y tuvieron que disolverse las Cámaras en virtud de las estipulaciones constitucionales que prevé el art. 99.5 CE. Además, también hemos tenido recientemente la presentación de una moción de censura, instituto de exigencia de la responsabilidad política que permanece inédito en nuestro sistema.

En un sistema parlamentario como el nuestro las relaciones entre Gobierno y Cortes son el eje de todo el sistema. Así, la Constitución de 1978, estableciendo una regulación directa y sistemática del Gobierno, dedica el Título IV al Gobierno y la Administración y el V a las relaciones entre el Gobierno y las Cortes Generales. Asimismo, preceptos incluidos en otros Títulos, que aluden al Gobierno, nutren la normativa constitucional sobre el poder ejecutivo. No obstante, la doctrina volcó muchas dudas sobre esta regulación, debido a la ruptura radical con la legislación anterior y a que dejaba ciertas zonas a la interpretación y al desarrollo legislativo

${ }^{2}$ Es interesante recoger la afirmación de Menéndez Pelayo: «Dos siglos de incesante y sistemática labor para producir artificialmente la revolución, aquí donde nunca podría ser orgánica, han conseguido, no renovar el modo de ser racional, sino viciarle, desconcertarle y pervertirle»: MENÉNDEZ Pelayo, M., Historia de los Heterodoxos Españoles, Madrid, 1963, Tomo IV, p. 508. 
posteriores $^{3}$. Y es que la clave para entender la naturaleza del Gobierno diseñado por la Constitución consiste en encuadrarlo en la unidad del sistema constitucional y en el conjunto de sus principios y valores.

El sistema parlamentario que nuestra Constitución crea se asienta sobre la doble confianza Parlamento-Gobierno. Desde su origen, la investidura del Presidente del Gobierno (art. 99 CE), el ejecutivo debe contar con la confianza del Congreso de los Diputados para existir como tal ${ }^{4}$. Además, el Gobierno ha de seguir contando a lo largo de todo su mandato con la confianza parlamentaria, puesto que las Cortes controlan políticamente al Gobierno y garantizan, en su faceta de impulso político, que se respete el pluralismo.

Este pluralismo significa, en el ámbito parlamentario, garantía de participación en el control y en las restantes competencias parlamentarias de los Grupos, al margen del número de miembros. En cierto sentido, las Cortes Generales se encargan de marcar los límites, condicionar y controlar la actuación del Gobierno. El planteamiento que nos ocupa necesita, sin embargo, ser matizado. Han pasado las épocas en que Parlamento y Gobierno estaban en lucha por detentar el poder y como señala TuDELA «hoy el Parlamento es escenario donde se representan los conflictos y las decisiones, pero no forjador de las mismas» y continúa «en la actualidad la dialéctica se plantea entre mayoría y minoría. La primera apoya al Gobierno sin cuestionarlo y, la segunda, se coloca políticamente como oposición, apoyando o no al Gobierno y ejerciendo la función de control, no como actividad parlamentaria, sino exclusivamente como resultado del enfrentamiento político que existe» ${ }^{5}$.

A lo largo del presente estudio veremos las dificultades en el proceso de investidura de un Presidente sin suficientes apoyos parlamentarios y la viabilidad de la exigencia de la responsabilidad política a través de una moción de censura.

\section{EL PROCESO DE INVESTIDURA DEL PRESIDENTE DEL GOBIERNO A LO LARGO DE LAS DIFERENTES LEGISLATURAS}

El proceso de investidura del actual Presidente del Gobierno, Mariano Rajoy Brey, fue uno de los más complejos desde la aprobación de la Constitución. El Congreso de los Diputados constituido después de las elecciones el 20 de diciembre de

\footnotetext{
3 Véanse las consideraciones de Garrido Falla, F., «Artículo 97», en Garrido Falla, F., Comentarios a la Constitución de 1978, Madrid, 1985, pp. 1364-1372.

${ }^{4}$ En relación a la elaboración del art. 99 «existió desde el primer momento un consenso general acerca de la inclusión en nuestro texto constitucional de un mecanismo de investidura parlamentaria del Gobierno»: Vírgala ForuRIA, E., La investidura parlamentaria del Gobierno: perspectiva comparada y Constitución española, Madrid, 2007, p. 264. Todos los debates constituyentes de este precepto pueden consultarse en esta obra, pp. 263 a 270.

5 Tudela Aranda, J., «La renovación de la función parlamentaria de control», Teoría y Realidad Constitucional, núm. 19, 2007, p. 76.
} 
2015 fue incapaz de otorgar su confianza al candidato propuesto por el Rey, Pedro Sánchez, teniendo que procederse a la disolución de las Cortes en virtud de lo previsto en el, hasta ese momento inédito, art. 99.5 CE. La nueva Cámara, elegida el 26 de junio de 2016, consiguió el 29 de octubre del mismo año llegar a un acuerdo en virtud del cual se pudo formar mayoría suficiente para permitir, según las previsiones del art. 99 CE, otorgar en segunda votación la confianza al candidato a la presidencia, procediéndose así a la formación de Gobierno.

En todo este proceso se han detectado algunas deficiencias en las previsiones constitucionales de la investidura ${ }^{6}$.

Una de esas deficiencias es, por ejemplo, el silencio del precepto acerca del plazo que ha de mediar desde que el cese del Presidente del Gobierno por cualquiera de los supuestos previstos en el art. $101 \mathrm{CE}$, hasta que exista propuesta de candidato por el Rey e, incluso, realizada la propuesta en qué plazo ha de convocarse el Pleno del Congreso. Salvo en el supuesto de dimisión del Presidente Suárez y la elección de un nuevo Presidente en la I Legislatura, en todas las demás Legislaturas, la sesión de investidura se ha celebrado al inicio de la Legislatura y, por ello, la propuesta ha tenido lugar a partir del momento en que el Congreso ha quedado constituido.

Esa propuesta supone ineludiblemente requisito necesario para que la Cámara se pronuncie y para que, en su caso, pueda entrar en funcionamiento la mencionada disolución prevista en el art. 99.5 CE, esto es, dos meses a contar desde la primera votación de investidura. En general, los tiempos que han mediado entre la sesión constitutiva de la Cámara y la propuesta de candidato por el Rey han sido bastante breves, desde los dieciséis días en la VI Legislatura hasta los tres días que mediaron en la IX Legislatura, y lo mismo cabe decir del plazo para la celebración del Pleno de investidura ${ }^{7}$. En este último punto, incluso se ha llegado a proponer una reforma

${ }^{6}$ Véase más ampliadas estas deficiencias en GiménEZ GLuCK, D., «El bloqueo, evitable de la formación del Gobierno: una propuesta de reforma del procedimiento de investidura», UNED. Revista de Derecho Político, núm. 99, mayo-agosto 2017, pp. 301-324.

7 En la I Legislatura se constituyó la Cámara el 22 de marzo de 1979 y el 28 de marzo el Rey propuso candidato a Adolfo Suárez (8 días). En la misma Legislatura, habiendo dimitido Suárez el 30 de enero de 1981, el Rey propuso candidato el 10 de febrero (11 días), celebrándose el debate de investidura de Calvo Sotelo el 18 de febrero. En la II Legislatura el Congreso se constituyó el 18 de noviembre de 1982 y el candidato fue propuesto el 26 del mismo mes ( 8 días), celebrándose la votación de investidura el 1 de diciembre. En la III Legislatura los plazos fueron brevísimos puesto que se constituyó el Congreso el 15 de julio de 1986, la propuesta quedó formalizada el 17 de julio (2 días) y la votación tuvo lugar el 23 de julio. La Cámara de la IV Legislatura se constituyó el 21 de noviembre de 1989, la propuesta se hizo el 27 de noviembre (6 días) y la investidura se votó el 5 de diciembre. El Congreso la V Legislatura quedó constituido el 29 de junio de 1993, el 3 de julio se propuso candidato (5 días) y el 9 de julio se votó la propuesta. En la VI Legislatura los plazos se dilataron bastante, la Cámara se constituyó el 27 de marzo de 1996, la propuesta se formuló el 12 de abril (16 días) y la sesión de investidura culminó con la votación celebrada el 3 de mayo. Los plazos en la VII Legislatura volvieron a ser muy breves, pues el 5 de abril de 2000 se constituyó la Cámara y la propuesta se recibió el 12 de abril (6 días), celebrándose la votación de investidura el 26 de abril. En la VIII Legislatura el Congreso celebró sesión constitutiva el 2 de abril de 2004, la propuesta de candidato tuvo lugar el 7 de abril (5 días) y la votación 
constitucional que incluya, no sólo plazo al Rey para proponer candidato sino «establecer otro plazo, de no más de cinco días desde la propuesta del Rey, para que él o los candidatos a presidente acudiesen a la Cámara a solicitar su confianza», condicionando así también la atribución del Presidente del Congreso de convocar el Pleno ${ }^{8}$.

Hasta este momento el mencionado art. 99 CE había cumplido perfectamente la finalidad que tiene, otorgar la confianza al candidato propuesto por el Rey, casi siempre en una primera votación con mayoría absoluta, y que éste pudiera formar Gobierno, o en su caso otorgar al candidato propuesto mayoría simple en una segunda votación?.

Esta cuestión está en íntima relación con la composición que hasta fechas recientes ha tenido la Cámara Baja. O como bien señala ARAGÓN «cabría preguntarse si el art. 99 de la CE solo podría funcionar en un escenario de bipartidismo o cuasibipartidismo» ${ }^{10}$. En gran medida como vamos a ir señalando los resultados electorales han permitido que con bastante facilidad se pudiera otorgar la confianza del Congreso al candidato propuesto por el Rey. Indudablemente, «la nota dominante del parlamentarismo en España en el entero período democrático ha sido su estabilidad y la consiguiente gobernabilidad»y, por eso, cuando se ha producido una «alteración del sistema de partidos» esto ha supuesto una repercusión clara «sobre la estabilidad y la gobernabilidad ${ }^{11}$.

En general, cuando el partido ganador de las elecciones no ha obtenido mayoría suficiente que le haya permitido gobernar en solitario, se ha buscado un acuerdo de investidura, esto es la formación de un Gobierno en minoría, no existiendo en nuestra reciente historia Gobiernos estatales en coalición ${ }^{12}$. La opción por esta fórmula, acuer-

para la investidura se celebró el 16 de abril. En la IX Legislatura el plazo fue desde el 1 de abril de 2008 fecha de la constitución de la Cámara al 4 de abril fecha de la propuesta (3 días), culminando el proceso con la segunda votación de investidura celebrada el 11 de abril. En la X Legislatura constituida la Cámara el 13 de diciembre 2011 la propuesta de candidato se realizó el 16 de diciembre (3 días) y la votación tuvo lugar el 20 de diciembre. Sobre las respectivas fechas de estos hechos además de la página web del Congreso de los Diputados puede consultarse Ripollés Serrano, M. ${ }^{a}$ R., «Artículo 171», en Ripollés Serrano, M. ${ }^{a}$ R. (Coord.), Comentarios al Reglamento del Congreso de los Diputados, Madrid, 2012, pp. 1174-1177.

${ }^{8}$ BlANCO VAldÉs, R., «El año que vivimos peligrosamente: del bipartidismo imperfecto a la perfecta ingobernabilidad», Revista Española de Derecho Constitucional, núm. 109, enero-abril 2017, p. 93.

${ }^{9}$ Las referencias exhaustivas a todos los procesos de formación de Gobierno en España desde la I Legislatura pueden verse en RENIU I Vilamala, J. M., La formación de gobiernos minoritarios en España (1977-1996), Madrid, 2002, pp. 97-109.

10 Aragón Reyes, M., «Legislatura fallida e investidura convulsa. Análisis y consecuencias», Revista Española de Derecho Constitucional, núm. 109, enero-abril 2017, p. 18.

${ }^{11}$ Blanco Valdés, R., op. cit., p. 77.

${ }^{12}$ La opción de los líderes de los partidos en favor solo de apoyar una investidura es la que como decimos se ha utilizado en España, pues en su caso «consideran que les será más beneficioso mantenerse fuera del Gobierno a incorporarse al mismo»: Reniu I Vilamala, J. M., «¿Merece la pena coaligarse? La formación de Gobiernos minoritarios en España, 1977-1996», Revista Española de Ciencia Política, núm. 5, octubre 2001, p. 114. Sí ha habido casos de coalición tanto en los Gobiernos autonómicos como en los ayuntamientos. Aunque faltan procesos electorales recientes véase Reniu I Vilamala, J. M. (Ed.), Los gobiernos de coalición de las Comunidades Autónomas Españolas, Madrid, 2014. 
dos puntuales para la investidura y para la aprobación de determinadas medidas legislativas, como presupuestos generales, Leyes Orgánicas o convalidación de Decretos Leyes ha sido la preferida por los candidatos minoritarios a la Presidencia del Gobierno, teniendo en cuenta que cuando se han producido esos acuerdos el número de apoyos que necesitaban para obtener la mayoría absoluta en primera votación era muy reducido.

En este sentido, sólo en cuatro de las hasta ahora doce legislaturas un solo partido ha obtenido la mayoría absoluta para no necesitar apoyos. Así, en la II Legislatura (1982-1986) Felipe González Márquez fue investido Presidente con 207 votos a favor de los cuales 201 eran de su partido, el PSOE ${ }^{13}$. Situación similar se vivió en la III Legislatura (1986-1989) cuando el mismo Presidente fue investido con los 184 votos que había obtenido el PSOE ${ }^{14}$. La situación no volvería a repetirse hasta la VII Legislatura (2000-2004) en la que José M. ${ }^{a}$ Aznar obtuvo la confianza del Congreso con 202 votos a favor de los cuales 183 eran de su partido, el Partido Popular (PP) ${ }^{15}$. Finalmente, en la X Legislatura (2011-2016), el candidato Mariano Rajoy Brey obtuvo también la confianza del Congreso con los 187 votos del Partido Popular (PP) ${ }^{16}$.

En el resto de las ocasiones los procesos de investidura han seguido situaciones diferentes.

En dos ocasiones el candidato obtuvo la mayoría necesaria contando con los votos de los partidos nacionalistas. Así sucedió en la V Legislatura (1993-1996), cuando Felipe González consiguió ser nombrado Presidente con los 159 votos del PSOE, más 17 votos de CiU y 5 de EAJ-PNV ${ }^{17}$. Situación similar otorgó la confianza al Presidente Aznar en la VI Legislatura (1996-2000) cuando además de los 156 votos del PP a favor, tuvo los 16 de CiU, 5 de EAJ-PNV y 4 de Coalición Canaria $(\mathrm{CC})^{18}$.

En ambos casos tanto PSOE como PP buscaron llegar a acuerdos para la formación de gobierno buscando el apoyo «en exclusiva hacia partidos regionalistas,

${ }^{13}$ El resultado de la votación fue: votos emitidos 345; a favor 207; votos en contra 116; abstenciones 21: DSCD núm. 4, de 1 de diciembre de 1982. A favor del candidato votaron los 201 del PSOE más 3 del Partido Comunista de España (PCE), 2 del Centro Democrático y Social (CDS) y 1 de Euskadiko Ezkerra.

${ }^{14}$ En este caso el resultado de la votación fue: votos emitidos 334; votos a favor 184; votos en contra 144; abstenciones 6: DSCD núm. 3, de 23 de julio de 1986.

${ }^{15}$ El resultado de la votación de investidura fue: votos emitidos 350; votos a favor 202; votos en contra 148; abstenciones 0: DSCD núm. 3, de 26 de abril de 2000. Votaron a favor del candidato los 183 diputados del PP, 15 de Convergencia i Unió (CiU) y 4 de Coalición Canaria (CC).

${ }^{16}$ En este último caso el resultado de la votación de investidura fue: votos emitidos 350; votos a favor 187; votos en contra 149; abstenciones 14: DSCD núm. 3, de 20 de diciembre de 2011.

${ }_{17}$ En la votación de investidura Felipe González consiguió 181 votos a favor; 165 votos en contra; y 1 abstención; de los 347 votos emitidos (DSCD núm. 3, de 9 de julio de 1993).

${ }^{18}$ José M. $^{a}$ Aznar fue investido Presidente con 181 votos a favor; 166 votos en contra y 1 abstención; de los 348 votos emitidos (DSCD núm. 3, de 4 de mayo de 1996). 
obviando la participación en la negociación del restante partido de ámbito nacional, Izquierda Unida» ${ }^{19}$.

En algunas otras ocasiones los acuerdos a los que ha llegado el candidato han sido acuerdos con varias formaciones dentro del arco parlamentario de un signo político similar al que pretendía formar Gobierno. El acuerdo se ha producido para obtener la mayoría absoluta en primera votación en los gobiernos de Suárez (I Legislatura 1979-1982) ${ }^{20}$ y de José Luis Rodríguez Zapatero (VIII Legislatura 2004-2008) ${ }^{21}$.

En varias ocasiones la investidura se ha producido mediante mayoría simple en segunda votación después de una primera votación en la que el candidato no ha podido obtener la mayoría absoluta prevista para la primera votación según las previsiones constitucionales del art. 99, como sucedió por primera vez en la IX Legislatura (20082011) con la investidura de Rodríguez Zapatero. Así fue en esa Legislatura cuando el candidato propuesto por el Rey, José Luis Rodríguez Zapatero sólo consiguió los apoyos de su partido el PSOE, suficientes para obtener la mayoría simple de la Cámara al haberse abstenido un elevado número de diputados ${ }^{22}$. En realidad, también el Presidente Calvo Sotelo había sido elegido años antes después de la segunda votación de investidura, pero en esa segunda votación obtuvo más votos que en la primera ${ }^{23}$.

19 De Montalvo JäÄSKeläInen, F., «Multipartidismo territorial y forma de gobierno parlamentaria: una visión de Derecho comparado», en Álvarez VÉlez, M. I. Y Alcón Yustas, M. a. F. (Coords.), Estado y Comunidades Autónomas en España: sistemas electorales y participación política, Madrid, 2011, p. 109

20 Adolfo Suárez fue nombrado Presidente del Gobierno después de haber recibido 183 votos a favor; 149 votos en contra; y 8 abstenciones; de los 340 votos emitidos (DSCD núm. 3, de 30 marzo de 1979). Votaron a favor de la propuesta además de los 168 diputados de la UCD, 8 de Coalición Democrática (CD), 5 del Partido Socialista de Andalucía (PSA), 1 del Partido Aragonés (PAR) y 1 de Unión del Pueblo Navarro (UPN). Las 8 abstenciones fueron de Convergencia i Unió (CiU).

${ }^{21}$ José Luis Rodríguez Zapatero 183; votos a favor 148 votos en contra; y 19 abstenciones; de los 350 votos emitidos: DSCD núm. 3, de 16 de abril de 2004. Los apoyos que recibió fueron 164 del PSOE, 5 de IU, 8 de Esquerra Republicana y además 3 de Coalición Canaria (CC), 2 de BNG y 1 de la Chunta aragonesista.

22 Efectivamente los resultados de la primera votación investidura fueron: votos emitidos 349; votos a favor 168; votos en contra 158; abstenciones 23 (DSCD núm. 3, de 9 de abril de 2008). Estos datos serían muy similares en la segunda votación: votos emitidos 350; votos a favor 169; votos en contra 158; abstenciones 23 (DSCD núm. 4, de 11 de abril de 2008). Los diputados del PSOE partido del candidato eran 169 .

${ }^{23}$ Así fue, la primera votación dio el siguiente resultado: votos emitidos, 344; a favor de la investidura, 169; en contra, 158, abstenciones, 17: DSCD núm. 145, de 20 de febrero de 1981. Sin embargo, el 23 de febrero cuando se estaba celebrando la segunda votación «y cuando eran aproximadamente las dieciocho horas y veinte minutos, tras escucharse en el pasillo algunos disparos y gritos de «iFuego, fuego!» y « $\mathrm{AAl}$ suelo todo el mundo!» irrumpe en el hemiciclo un número elevado de gente armada y con uniforme de la Guardia Civil, que se sitúa en lugares estratégicos, amenaza por la fuerza a la Presidencia y, tras un altercado con el Vicepresidente Primero del Gobierno, Teniente General Gutiérrez Mellado, conmina a todos a tirarse al suelo, sonando ráfagas de metralleta. Queda interrumpida la sesión»: DSCD núm. 146, de 23 de febrero de 1981. Reanudada la votación de investidura dos días después, el candidato a la Presidencia fue investido Presidente del Gobierno con los votos a favor de 186 diputados, 158 en contra y ninguna abstención, de los 344 votos emitidos: DSCD núm. 147, de 25 de febrero de 1981 . 
Muy peculiares han sido tres procesos de investiduras, especialmente los sucedidos en las dos últimas Legislaturas.

El primer proceso de investidura polémico y, por ello, peculiar, se produjo en la IV Legislatura (1989-1993). El Pleno del Congreso en el momento en que iba a celebrarse la sesión de investidura quedó integrado por 332 diputados al haber prosperado varios recursos contenciosos electorales que anularon las elecciones en Melilla, Murcia y Pontevedra, por lo que estaban pendientes de ser designados 14 escaños y además 4 diputados de Herri Batasuna no tomaron posesión de su escaño en toda la Legislatura ${ }^{24}$. El Presidente de la Cámara estimó en interpretación del art. 20.2 del Reglamento de la Cámara que la mayoría absoluta debía contabilizarse sobre los 332 diputados y no sobre los 350 que constituyen el Congreso, lo que permitió la investidura de Felipe González²5.

El segundo proceso de investidura con una cierta novedad lo hemos vivido recientemente en la XI Legislatura, conocida como la Legislatura fallida y que comenzó el 13 de enero y terminó el 19 de julio de 2016. El Rey propuso como candidato a Pedro Sánchez Pérez-Castejón, que solicitó la confianza de la Cámara ${ }^{26}$. El candidato se sometió a las dos votaciones preceptivas, y al no ser viable obtener la investidura, se disolvieron las Cortes Generales en cumplimiento de lo previsto en el art. 99.5 $\mathrm{CE}^{27}$.

Finalmente, la investidura del actual Presidente Mariano Rajoy ha sido, me atrevería a decir, de las más atípicas de todas las vividas desde la vigencia de la Constitución de 1978. Terminada la ronda de consultas del Rey con los representantes políticos en el Congreso de los Diputados, a finales de julio de 2016, propuso como

${ }^{24}$ Sobre este tema de los diputados de Herri Batasuna tuvo ocasión de pronunciarse el Tribunal Constitucional en su Sentencia 119/1990, de 21 de junio. También puede leerse el interesante comentario de Santaolalla, F., «El juramento y los reglamentos parlamentarios (Comentario a la STC 119/1990, de 21 de junio)», Revista Española de Derecho Constitucional, núm. 30, septiembre-diciembre 1990, pp. 149-159.

25 Así el resultado de la votación de investidura fue: votos emitidos 328; a favor 167; votos en contra 155; abstenciones 6 (DSCD núm. 3, de 5 de diciembre de 1989). Votaron a favor del candidato los 166 diputados del PSOE, más 1 representante de las Agrupaciones Independientes de Canarias.

26 El pasado 22 de enero de 2016 concluida la primera ronda de consultas del Rey Felipe VI sin ser viable proponer un candidato a la Presidencia, se reunió nuevamente con el Presidente del Congreso a fin de comenzar una segunda ronda de consultas que concluyó con la propuesta el 2 de febrero de un candidato a la Presidencia, esto es, un plazo de 20 días, desde el 13 de enero que se celebró la sesión constitutiva del Congreso de los Diputados, plazo inédito en nuestra historia constitucional.

27 En la primera votación los resultados fueron: votos emitidos 350; votos a favor 130; votos en contra 219; abstenciones, 1 (DSCD núm. 3, de 2 de marzo de 2016). Votaron a favor del candidato los 89 diputados del PSOE, más los 40 de Ciudadanos. El resultado de la segunda votación fue: votos emitidos 350; votos a favor 131; votos en contra 219; abstenciones, 0 (DSCD núm. 4, de 4 de marzo de 2016). A los votos a favor que había obtenido en la primera votación se unió un diputado de Coalición Canaria (CC). Las Cortes se disolvieron por Real Decreto 184/2016, de 3 de mayo, de disolución del Congreso de los Diputados y del Senado y de convocatoria de elecciones (BOE núm. 107, de 3 de mayo de 2016). 
candidato a la Presidencia al en ese momento Presidente en funciones, Mariano Rajoy $^{28}$. La sesión de investidura fue convocada para finales de agosto. Se produjeron así dos votaciones sobre esa propuesta. En la primera votación de investidura el candidato no consiguió obtener la mayoría absoluta exigida, pero en la segunda votación celebrada cuarenta y ocho horas después tampoco consiguió la mayoría simple necesaria para formar Gobierno ${ }^{29}$. A finales de octubre el Rey realizó una nueva ronda de consultas y reiteró su propuesta de candidato por lo que se produjeron nuevas votaciones en el Congreso. En esta segunda ocasión, Rajoy no obtuvo la confianza por mayoría absoluta en la primera votación ${ }^{30}$, pero sí obtuvo la mayoría simple en la segunda $^{31}$, al abstenerse el Partido Socialista ${ }^{32}$.

Hasta aquí el desarrollo de los diferentes procesos de investidura. Ahora queda pendiente saber cómo es viable la gobernabilidad con un Gobierno minoritario y en gran medida inestable, en una Cámara fragmentada políticamente. Es cierto que nuestro sistema político ha tenido un bipartidismo aparente, puesto que en varias ocasiones ha sido complicado alcanzar mayorías sólidas de gobierno, e incluso, la mayoría simple del partido ganador ha tenido que apoyarse en un tercer partido, lo

${ }^{28}$ En general los textos constitucionales hacen referencia a que el Gobierno en funciones seguirá con los asuntos de trámite u ordinarios hasta la toma de posesión del nuevo Gobierno. Otro país con experiencia en estas situaciones de inestabilidad es Italia, hasta el punto que los italianos han acuñado el dicho «senza Governo si sta meglio» (sin gobierno es mejor). Paradigmático fue hace unos años el caso belga, pues desde junio de 2010 hasta el 6 de diciembre de 2011, transcurrieron 541 días de Gobierno en funciones. Situaciones similares se vivieron en Moldavia (528 días entre 2015 y 2016), Camboya (entre 2003 y 2004, 343 días), en Irak (en el año 2009, 249 días) y en los Países Bajos (en el año 1977, 207 días). Sobre el tema del Gobierno en funciones y en concreto sobre el control en esa etapa vid. Álvarez Vélez, M. I., «El control parlamentario: las incertidumbres sobre el control de un Gobierno en funciones», Asamblea. Revista Parlamentaria de la Asamblea de Madrid, núm. 35, diciembre de 2016, pp. 26-43.

29 Los resultados en la primera (DSCD núm. 3, de 31 de agosto de 2016) y en la segunda votación (DSCD núm. 4, 2 de septiembre de 2016) fueron idénticos: votos emitidos 350; votos a favor 170; votos en contra 180; abstenciones 0. En las dos votaciones votaron a favor del candidato además de los 134 diputados del PP, 32 de Ciudadanos, 1 de Unión del Pueblo Navarro (UPN), 1 de Coalición Canaria y 1 de Foro de Ciudadanos.

30 Votos emitidos 350; votos a favor 170; votos en contra 180; abstenciones 0: DSCD núm. 13, de 27 de octubre de 2016. Los apoyos fueron los mismos que en la votación de la primera propuesta: 134 diputados del PP, 32 de Ciudadanos, 1 de Unión del Pueblo Navarro (UPN), 1 de Coalición Canaria y 1 de Foro de Ciudadanos.

31 Votos emitidos 349; votos a favor 170; votos en contra 111; abstenciones 68: DSCD núm. 14, de 29 de octubre de 2016.

32 «La decisión del PSOE de abstenerse, que es lo que hizo posible la investidura (habida cuenta de que ya se contaba, desde el primer momento poselectoral, con el apoyo de Ciudadanos) se adoptó a costa de una grave crisis orgánica en el seno de aquel partido. El cambio de actitud del PSOE (del no rotundo mantenido desde la misma noche electoral del 20 de diciembre de 2015 a la abstención acordada por el comité federal después de la salida traumática del entonces secretario general del partido) le supuso una auténtica convulsión interna y, en tal sentido, la constatación de que las reglas políticas (necesidad de pactos para gobernar) no funcionaron con regularidad, esto es, con normalidad, sino de manera traumática»: Aragón ReYes, M., op. cit., p. 26. 
que «provoca gobiernos en los que el pacto de gobernabilidad es sumamente débil»» ${ }^{33}$. Veamos ahora lo que ha sucedido con los instrumentos que hay en nuestra Constitución para la exigencia de la responsabilidad política al Gobierno.

\section{ACERCA DE LA EFICACIA DE LOS MECANISMOS DE EXIGENCIA DE LA RESPONSABILIDAD POLÍTICA: LA CUESTIÓN DE CONFIANZA Y LA MOCIÓN DE CENSURA}

En un sistema parlamentario como el nuestro, además de la función de control ordinaria, la Constitución crea dos figuras que culminan la relación Congreso-Gobierno, la moción de censura y la cuestión de confianza, que suelen vincularse a la exigencia de responsabilidad política del Gobierno y que en su caso están en íntima relación con el procedimiento de investidura del Presidente que acabamos de relatar.

Así, el art. 114 CE considera que «el Congreso de los Diputados puede exigir la responsabilidad política del Gobierno mediante la adopción por mayoría absoluta de la moción de censura», quedando así este instituto vinculado directamente al contenido de los preceptos del art. $108 \mathrm{CE}$ que otorga al Congreso la exigencia de dicha responsabilidad. Si la moción no prospera, conforme al procedimiento establecido en los arts. 113 y $114.2 \mathrm{CE}$, no hay duda que la posición del Presidente queda reforzada. No obstante, la moción no es un instrumento parlamentario diseñado para la renovación de la confianza al Presidente, por el contrario, representa la insatisfacción parlamentaria con la política presidencial, al menos de una parte de la Cámara, la búsqueda de un nuevo Presidente y de una política presidencial diferente.

La cuestión de confianza presenta, asimismo, muchas dificultades para considerarla adecuada para la renovación de la confianza parlamentaria. Y realmente no constituye una fórmula para la exigencia de la responsabilidad política del Gobierno, sólo podría tener cierta utilidad para esta función, si se dieran las circunstancias políticas necesarias para que el Presidente no alcanzase la mayoría simple de la Cámara, tras el planteamiento de la cuestión (art.112 CE). Una situación extrema, para el Presidente, y para su Gobierno y, sin duda, derivada de una situación anterior a la presentación de la cuestión y que ésta materializa.

En realidad, la cuestión de confianza debería haber sido la herramienta más acorde para la renovación de la confianza parlamentaria. No obstante, la eficacia de la «cuestión» se paraliza debido a que la iniciativa para su planteamiento corresponde exclusivamente al Presidente, aunque sea preceptiva «la previa deliberación del Consejo de Ministros». La cuestión de confianza constituye un acto discrecional del Presidente, que la decidirá por razones de conveniencia política, pues no hay supuesto constitucional que obligue a solicitarla (112 CE).

33 De Montalvo JäÄskeläInen, F., op. cit., p. 111. 
Así es. Durante el proceso constituyente la cuestión de confianza se entendió como un medio para que el Presidente reforzase su posición ante el Congreso, e indirectamente ante la opinión pública. Efectivamente, es un modo de renovar la confianza obtenida, puesto que el Presidente debe solicitarla «sobre su programa o sobre una declaración de política general», expresión que evoca el planteamiento constitucional de la sesión de investidura. Sin embargo, en la práctica, la eficacia de la «cuestión» como instrumento de control y de renovación del apoyo de la Cámara es muy débil, debido, por una parte, a la configuración que ha recibido de la propia Constitución y, por otra, al desarrollo en la práctica de un parlamentarismo excesivamente rígido. Así, el Presidente no está obligado a presentar la cuestión de confianza, por deteriorados que estén el prestigio y la imagen del Gobierno, sino que esta iniciativa queda a su criterio y a la influencia que, en su caso, pueda recibir de los demás miembros de su equipo. Y en la práctica, el deseo de fortalecer unos partidos políticos emergentes, necesariamente débiles en el momento de la transición, priorizaron el modelo de partidos fuertes lo que no facilitó una reflexión sobre la creación de un sistema que propiciase una actividad parlamentaria fértil. Por el contrario, la influencia de las estructuras políticas mayoritarias ha suprimido, hasta ahora, la expresión de un pluralismo adelantado y dinámico.

En cuanto a la votación prevista para el otorgamiento de la confianza, el texto del Anteproyecto constitucional no la contemplaba, ya que sólo se preveía el planteamiento de la cuestión ante la Cámara: «El Presidente del Gobierno previa deliberación del Consejo de Ministros, puede plantear ante el Congreso de los Diputados la cuestión de confianza sobre su programa o sobre una declaración de política general». Fue en el Informe de la Ponencia donde se incluyó la votación, exigiendo mayoría absoluta de la Cámara ${ }^{34}$. En el Congreso esta redacción del actual 112 CE no dio lugar a deliberación. Sin embargo, en el Senado, el Grupo de Unión de Centro Democrático solicitó que se modificara la dicción del precepto, de modo que se considerase otorgada la confianza por mayoría simple y no absoluta, lo que se recogió en el contenido definitivo, arguyendo la incoherencia que representaba requerir en segunda votación mayoría simple para la investidura y, sin embargo, que se requiriera mayoría absoluta para el otorgamiento de la confianza solicitada por el Presidente.

También es de interés la propuesta de la Agrupación Independiente del Senado, que defendió su portavoz, Senador Ollero, de cuyas palabras se desprende, también, el concepto que los constituyentes tenían del uso de la cuestión de confianza como instrumento parlamentario e, incluso, del que tenían sobre las relaciones entre el Presidente del Gobierno y el Congreso, afirmando que si se mantenía la exigencia de la mayoría absoluta para obtener la confianza solicitada a través de una cuestión, «... lo que sucederá en el caso de que el Gobierno sea minoritario es que rectificará su programa cuantas veces estime conveniente, sin plantear en circunstancia alguna la cuestión de confianza. Tendremos entonces un Gobierno minoritario, un Gobierno

34 BOCG núm. 82, de 17 de abril de 1978. 
estable, pero un Gobierno débil, por no poder acudir a la Cámara, y un Gobierno prácticamente irresponsable (...). La solución que proponemos entendemos nosotros que es sencilla y razonable la confianza se entenderá otorgada cuando vote a su favor la misma mayoría de diputados que aprobó la investidura del Presidente del Gobierno» ${ }^{35}$. Así, se ha señalado que la cuestión de confianza «constituye una notable garantía para las minorías» $\mathrm{y}$ «permite la publicidad de un debate que ha de producirse en el Pleno del Congreso» ${ }^{36}$.

La otra vía de exigencia de la responsabilidad política del Gobierno es la moción de censura. La elección del Presidente mediante la adopción de una moción de censura por los miembros del Congreso de los Diputados, debe considerarse un procedimiento extraordinario de elección y, de hecho, ninguno de los Presidentes del Gobierno, en casi cuarenta años de vigencia de la Constitución, como hemos ido viendo, ha sido nombrado tras dicho procedimiento. La moción de censura se regula en el art. $113 \mathrm{CE}$, aunque los efectos de la adopción se establecen en el art. 114.2 CE. En cuanto a su sentido político hay que tener en cuenta lo establecido en el art. $108 \mathrm{CE}$ que otorga al Congreso de los Diputados atribuciones para la exigencia de la responsabilidad de la gestión política del Gobierno.

La vocación del instituto procede del deseo de los constituyentes europeos, tras la Segunda Guerra Mundial, de establecer mecanismos racionalizados de control de los órganos ejecutivos por los Parlamentos. La opción de 1978 secunda lo establecido en el art. 67 de la Ley Fundamental de Bonn, en cuyos preceptos se inspiraron los constituyentes españoles ${ }^{37}$. Su principal característica se expresa en el concepto de «moción de censura constructiva», que invoca el requisito constitucional que exige que la moción incluya un candidato a la Presidencia del Gobierno.

La moción constituye una iniciativa exclusivamente parlamentaria que comienza, a diferencia del procedimiento ordinario de elección del Presidente, sin intervención del Rey. La moción se presenta en la Mesa de la Cámara por al menos la décima parte de los Diputados, mediante escrito motivado que ha de incluir un postulante a la Presidencia que haya aceptado expresamente la candidatura (art. 175.2 RCD). Una vez admitida a trámite, la moción despliega las cautelas previstas en el art. 115.2 CE, ya que a partir de ese momento el Presidente del Gobierno no puede proponer al Rey la disolución de la Cortes Generales.

El constituyente exige un plazo de cinco días entre la presentación de la moción y su votación, conforme a lo establecido en el art. 113.3 CE, de modo que se ofrece

35 DSS núm. 50, de 6 de septiembre de 1978, pp. 2377 y 2378. Consultar también: Ollero, C., Derecho y Teoría Política en el Proceso Constituyente, Madrid, 1986, pp. 104 y 105.

36 Sánchez Navarro, Á., La oposición parlamentaria, Madrid, 1997, p. 246.

37 Sobre la Ley Fundamental de Bonn como precedente directo de la moción de censura prevista en la Constitución Española de 1978, vid. Vírgala Foruria, E., La moción de censura en la Constitución de 1978 ( y en la historia del parlamentarismo español), Madrid, 1988, pp. 115-145. Para un estudio de los tipos de moción de censura en Europa: SÁNCHEz De Dios, M., La moción de censura. (Un estudio comparado), Madrid, 1992. 
un tiempo prudencial para la reflexión, dada la trascendencia política del hecho. Asimismo, la Constitución prevé la presentación de mociones alternativas durante los dos días siguientes a la presentación de la primera, con los mismos requisitos ${ }^{38}$. Sobre este punto piensa Vírgala que nada se opone a que los mismos Diputados que hayan suscrito la primera moción, firmen otras, pues se trata de buscar candidatos con apoyos parlamentarios suficientes para alcanzar un cambio de Gobierno, aunque es evidente que las mociones alternativas «han de variar respecto a la originaria obligatoriamente bien en el candidato, bien en la motivación» ${ }^{39}$. No obstante, si una moción de censura es rechazada, los Diputados firmantes no podrán presentar otra en el mismo período de sesiones (art. 113.4 CE).

En cuanto al procedimiento parlamentario de la moción, el art. 177 RCD regula las fórmulas de debate y votación. El primero se inicia con la intervención, sin limitación de tiempo, de uno de los Diputados que han suscrito la moción de censura, «a continuación y también sin limitación de tiempo, podrá intervenir el candidato propuesto en la moción para la Presidencia del Gobierno, a efectos de exponer el programa político del Gobierno que pretende formar» (art.177.1 RCD). La redacción de dicho precepto conlleva la idea de que el candidato no está obligado a exponer su programa, por lo que podría no intervenir y, en esta línea, considera REVENGA, que aunque la Cámara debe conocer el programa del candidato, sería aceptable una interpretación de dicho precepto reglamentario «en el sentido de que es posible diferir la profundización de la línea programática a un momento posterior al nombramiento» ${ }^{40}$.

No obstante, toda interpretación restrictiva de dicho precepto reglamentario, que permitiera al candidato no ofrecer a la Cámara la totalidad de la información sobre su programa resultaría contradictoria con lo exigido por la propia Constitución para la elección del Presidente conforme al procedimiento establecido en el art. 99 CE, pues la exposición del candidato constituye una obligación, y alrededor de ella, se construye la confianza parlamentaria para la investidura. Este es el espíritu de la Constitución y no hay razones para entender que con la elección del Presidente del Gobierno mediante la adopción de una moción de censura podría degradarse estas exigencias. Resulta también poco creíble que un candidato a la Presidencia rehúse presentar su programa y que, si se produjera esta circunstancia, la moción fuera votada favorablemente.

Tras la exposición del candidato y la interrupción decretada por la Presidencia, corresponde a los representantes de los Grupos Parlamentarios, que lo hayan solici-

38 Durante el proceso constituyente el Senador Sánchez Agesta defendió una enmienda tendente a suprimir las mociones alternativas, alegando falta de claridad, puesto que entendía que no se regulaba suficientemente si las mociones alternativas se referían a las que tienen distinta motivación, a las previamente presentadas o a las que presentan un distinto candidato a la Presidencia del Gobierno. DSS núm. 50, 1978, p. 2365.

39 Vírgala Foruria, E., La moción de censura en la Constitución de 1978, cit., p. 245.

40 Revenga Sánchez, M., La formación del Gobierno en la Constitución española de 1978, Madrid, 1988, pp. 50 y 51. 
tado, participar en el debate por un tiempo de treinta minutos. Además, «todos los intervinientes tienen derecho a un turno de réplica o rectificación de diez minutos» (art. 177.2 RCD).

En caso de mociones alternativas, el Presidente de la Cámara, oída la Junta de Portavoces, podrá acordar «el debate conjunto de todas las incluidas en el orden del día, aunque habrán de ser puestas a votación por separado, siguiendo el orden de su presentación» (art. 177.3 RCD).

La moción requiere mayoría absoluta de la Cámara para su aprobación, y si se llega a aprobar una de las presentadas, las restantes que se hubieran presentado no se someten a votación (art. 177.5 y 6 RCD).

Se aprecia, en los procedimientos constitucional y reglamentario del desarrollo de la moción, el protagonismo del candidato, o candidatos, a la Presidencia, protagonismo que también encontramos en el desarrollo del procedimiento de elección del Presidente del Gobierno mediante las disposiciones contenidas en el art. $99 \mathrm{CE}$, es decir, por el procedimiento ordinario. La cuestión es que, en este último caso, el protagonismo del candidato está justificado, puesto que es el candidato designado por el Rey y sobre el que recae la atención de la Cámara que desea conocer su programa y confirmar que merece la confianza que solicita. Por el contrario, en la moción de censura, la presentación de un candidato alternativo, como elemento definitorio del modelo de la «moción constructiva» no debería encubrir que su principal objeto es la exigencia de la responsabilidad política de un Presidente del Gobierno en plenitud de funciones, y la atención de la Cámara debería centrarse en evaluar la gestión la política desarrollada desde su nombramiento y no en el candidato.

En realidad, la experiencia de la moción de censura constructiva ofrece, en el ámbito del constitucionalismo comparado, un panorama de dudosa eficacia y, en el terreno de la teoría ha recibido importantes críticas de la doctrina. Señalan MonTero Gibert y García Morillo que «el propio requisito constructivo implica un cierto desconocimiento de la lógica del sistema parlamentario al unir artificialmente dos operaciones de naturaleza y contenido diferentes como son la investidura y la censura $»^{41}$. Otros autores han insistido también en lo inadecuado de la interrelación que se produce entre la exigencia de la responsabilidad política y la postulación de un nuevo candidato a la presidencia del Gobierno, incluso en la votación de la moción $^{42}$. También se ha señalado que «la moción de censura fue concebida, desde su mismo nacimiento, como un remiendo para cubrir las deficiencias del sistema de partidos» ${ }^{43}$.

Por último, el art. 114.2 CE establece los efectos de la adopción de una moción de censura por el Congreso de los Diputados. El Gobierno ha de presentar su dimisión

${ }^{41}$ Montero Gibert, J. R. y García Morillo, J., El control parlamentario, Madrid, 1984, p. 161.

42 Cfr. Mellado Prado, P., La responsabilidad política del Gobierno en el ordenamiento español, Madrid, 1988, pp. 294 y ss.

${ }_{43}$ SIMÓN YARZA F., «La moción de censura: ¿constructiva u «obstructiva»?», Revista Española de Derecho Constitucional, núm. 103, enero-abril 2015, p. 99. 
al Rey y el candidato incluido en la moción se entiende investido de la confianza de la Cámara a los efectos previstos en el art. 99 CE.

En realidad, los dos mecanismos que estamos estudiando han tenido muy poca relevancia en el ámbito estatal. Hasta la fecha se han presentado dos cuestiones de confianza, que han sido satisfactorias para el Presidente de turno ${ }^{44}, y$ tres mociones de censura, todas ellas fallidas ${ }^{45}$.

La primera ocasión en que se solicitó la cuestión de confianza fue en los inicios de nuestro sistema democrático. El Presidente Suárez en la I Legislatura solicitó en septiembre de 1980 la confianza al Congreso, que se debatió entre el 16 y el 18 de septiembre, para lo que se articuló por parte de la Presidencia de la Cámara «una resolución en la que se especifiquen las normas con arreglo a las cuales tendrá lugar el debate y votación de la cuestión de confianza solicitada» ${ }^{46}$. En realidad, el Presidente utilizó este mecanismo «instrumentalizándose como un cauce de refuerzo de una posición gubernamental muy debilitada en aquel preciso momento por mor de una moción de censura presentada por la oposición socialista unos meses antes, y que aunque no llegó a ser aprobada, dejó al Gabinete en minoría en el seno de la Cámara» ${ }^{47}$. En realidad, se ha señalado que «su objetivo primordial fue intentar restaurar ante la opinión pública la imagen del Gobierno, desgastada tras la moción de censura presentada por el PSOE contra el presidente cuatro meses antes» ${ }^{48}$. Y en cierta medida fue lo que consiguió puesto que en la votación recibió más apoyos de los que había obtenido en la mencionada moción de censura, como veremos más tarde, esto es, 180 , frente a los 166 que habían rechazado la moción ${ }^{49}$.

La segunda cuestión de confianza la solicitó el Presidente González, que como señalamos fue elegido en un Pleno en el que no habían adquirido el acta de diputados

44 Pero «ni la una ni la otra se dirigieron a cohesionar la mayoría parlamentario-gubernamental, la verdadera finalidad de esa institución constitucional»: Blanco VALDÉs, R., op. cit., p. 75.

${ }^{45}$ Por lo que respecta a la República Federal de Alemania se han presentado dos mociones de las que triunfó una: Elías MÉNDEz, C., La moción de censura en España y Alemania (Estado, Länder y Comunidades Autónomas), Madrid, 2005, pp. 63-67.

46 BOCG núm. 37-1, de 10 de septiembre de 1980. Véase el debate en DSCD núm. 109, de 16 de septiembre de 1980 .

47 Fernández SEgado, F., «La cuestión de confianza: marco jurídico-constitucional y praxis política», Revista Española de Derecho Constitucional, núm. 21, septiembre-diciembre 1987, p. 43.

48 Blanco Valdés, R., op. cit., p. 75.

49 En la cuestión de confianza los resultados fueron: votos emitidos 346; votos a favor 180; votos en contra 164; abstenciones 2: DSCD núm. 111, de 18 de septiembre de 1980. Por su parte, la moción de censura presentada unos meses antes con Felipe González como candidato arrojó el siguiente resultado: votos emitidos 339 (no asistieron once diputados: vasco-PNV, un miembro de Minoría Catalana y, por el mixto, los tres diputados de Herri Batasuna); votos a favor de la moción 152 (socialistas, comunistas, andalucistas y, por el mixto, Bandrés, Fernández, Pi Súñer y Sagaseta); votos en contra de la moción 166 (centristas); abstenciones 21 (Coalición Democrática, Minoría Catalana y, por el mixto, Aizpún, Clavero, Gómez de las Roces, Molins y Piñar): DSCD núm. 95, de 30 de mayo de 1980 y GónZalo GonZÁLEZ, M., «Crónica y documentación parlamentarias», Revista del Departamento de Derecho Político, núm. 7, otoño 1980, p. 207. 
algunos representantes. Así en el debate de su investidura el Presidente se «comprometió a plantear la cuestión de confianza una vez resueltos los contenciosos electorales que había pendientes». En la presentación el Presidente «señaló que daba cumplimiento a su compromiso con esta cuestión de confianza sobre una declaración de política general, ya que no pretendía reiterar el programa que se planteó y debatió durante la sesión de investidura» y, por ello centró su atención a lo largo de su discurso en los aspectos más relevantes del desafío del 93 y sus exigencias internas y externas, así como en el espíritu de diálogo que pretendía mantener con las fuerzas parlamentarias durante la legislatura» y obtuvo en esa votación mayoría absoluta de la Cámara contabilizada está vez sí sobre el total de los miembros de la Cámara ${ }^{50}$.

La moción de censura al Presidente Suárez había sido presentada por los Grupos Parlamentarios Socialistas del Congreso, Socialistes de Catalunya y Socialistas Vas$\cos ^{51}$. Fue suscrita por treinta y seis Diputados e incluía como candidato a la Presidencia al Diputado Felipe González. En el documento de presentación de la moción los firmantes la justifican por la «grave crisis por la que atraviesa la sociedad española, en la construcción del Estado democrático y de las autonomías, en la seguridad ciudadana y en el ejercicio de las libertades fundamentales, en la situación social de paro e inflación, en la falta de definición de nuestro papel en el mundo y en el distanciamiento y desconfianza que estos graves problemas producen en la ciudadanía», y por entender que además de todas estas cuestiones quedaba « suficientemente probada la incapacidad del Presidente Suárez y su Gobierno para dirigir los destinos de la nación española» ${ }^{52}$. A falta de regulación parlamentaria la Presidencia del Congreso dictó la Resolución de 28 de mayo de 1980, que estableció las normas del debate, basadas en el Anteproyecto de Reglamento de la Cámara ${ }^{53}$.

En este caso, similar a lo que también ha sucedido en las otras dos mociones, el debate se centró en la figura del candidato y no en las críticas al Gobierno o a su Presidente. En realidad, la finalidad de los firmantes no era la finalidad que tiene una moción de este tipo: sustituir al Presidente y cambiar el Gobierno. La pretensión era

${ }^{50} \mathrm{El}$ resultado fue: votos emitidos 343; votos a favor 176; votos en contra 130; abstenciones 37 (DSCD núm. 28, de 5 de abril de 1990). Vid. El relato de las intervenciones además de en el Diario de sesiones en Mellado Prado, P., «Crónica parlamentaria del Congreso de los Diputados», UNED. Revista de Derecho Político, núm. 32, 1991, pp. 223-236.

${ }^{51}$ BOCG núm. 403-1, de 13 de junio de 1980.

52 Además de estos motivos, señala GoNZALO «el terrorismo y la criminalidad prosperan, en cuanto no decrecen, aparte de que determinados procedimientos por desacato o por apología del terrorismo y la denegación de licencia a una película sobre el crimen de Cuenca se estima que son síntoma de una interpretación restrictiva, cuando no vulneratoria, de la Constitución; el curso a seguir en política de autonomías no se ve claro, por el tema de las competencias exclusivas o excluyentes, el de las comisiones de transferencias o el proceso de implantación de comunidades autónomas en todo el territorio español; en fin, la situación económica no mejora, puesto que el paro crece, aunque la inflación se contenga, y la confianza se deteriora a pesar de lo positivo del pacto entre Unión General de Trabajadores y Confederación Española de Organizaciones Empresariales»: GonZalo GonZÁlez, M., op. cit., p. 188.

53 BOCG, núm. 31-I, de 13 de junio de 1980. 
marcadamente política, pues «los socialistas buscaban fundamentalmente tres cosas: forzar al resto de las fuerzas políticas a una clarificación de su postura respecto del Gobierno, mostrar a la opinión pública los fallos del Gobierno y su pérdida de apoyos parlamentarios en relación a la investidura y, finalmente, presentar la alternativa socialista de cara a unas futuras elecciones generales» ${ }^{54}$. Y efectivamente, la alternativa a esta moción por parte del Presidente Suárez fue la presentación, poco después, de una cuestión de confianza puesto que con la moción había quedado enormemente debilitado ante la opinión pública ${ }^{55}$.

La segunda moción de censura se presentó en marzo de 1987, contra el Presidente González e incluía como candidato a la Presidencia al Senador Antonio Hernández Mancha. La formalización de la moción de censura se realizó mediante la presentación, ante la Mesa del Congreso, de un escrito firmado por 51 diputados del Grupo Popular, que incluía un candidato alternativo a la Presidencia del Gobierno, y especificaba los motivos que fundamentaban aquélla: deficiente funcionamiento de los servicios del Estado; ineficaz gestión económica; ineficacia e inadecuación de la Administración Central; errática política exterior y de defensa; actitud hegemónica e intervencionista del Estado y ausencia de cauces de diálogo ${ }^{56}$.

Es importante señalar que esta moción de censura fue de todo punto de vista un fracaso. Así «si el debate sobre la moción de censura de 1980 se convirtió rápidamente en un debate sobre el programa político del candidato alternativo, no ocurrió lo mismo durante el debate de 1987, ya que la mayoría de los representantes de los Grupos Parlamentarios se limitaron a criticar nuevamente al Gobierno, ignorando prácticamente al candidato alternativo y su programa político de Gobierno» ${ }^{57}$. El partido del Gobierno tenía mayoría absoluta, por lo que la moción fue rechazada por 67 votos a favor, 195 en contra y 71 abstenciones ${ }^{58}$. Con esta moción los firmantes no consiguieron ninguno de los objetivos propuestos, teniendo en cuenta además que su presentación «no sólo no desgastó ni quebrantó la imagen de la mayoría del Partido Socialista y de su Gobierno, sino que éste salió considerablemente fortalecido» y, en definitiva, la moción tuvo para el Grupo Popular «un efecto boomerang, ya que se volvió contra los propios defensores de la moción» ${ }^{59}$, y "por su parte, Hernández Mancha, que no era diputado, fracasó tan estrepitosamente en su intento de desgastar

54 Vírgala Foruria, E La moción de censura en la Constitución de 1978, cit., p. 279.

55 Vírgala Foruria, E., «La moción de censura de 1987: segunda práctica aplicativa del artículo 113 de la Constitución», Revista de las Cortes Generales, núm. 13, 1988, p. 174.

56 BOCG, núm. 56, de 26 de marzo de 1987.

57 Mellado Prado, P., «Crónica parlamentaria del Congreso de los Diputados», UNED. Revista de Derecho Político, núm. 26, 1988, p. 158.

58 DSCD núm. 40, de 30 de marzo de 1987.

59 Mellado Prado, P., op. cit., p. 158. Además, es interesante leer las opiniones periodísticas que se produjeron sobre la moción y especialmente sobre la figura del candidato en Vírgala ForURIA, E., La moción de censura en la Constitución de 1978, cit., p. 287 y 288 así como en Vírgala Foruria, E., «La moción de censura de 1987: segunda práctica aplicativa del artículo 113 de la Constitución», cit., pp. 159-177. 
a González y al gobierno del PSOE que, de hecho, el debate de investidura fue en gran medida el canto del cisne del entonces recién elegido líder de $\mathrm{AP}_{»}{ }^{60}$.

La tercera y última moción de censura se ha presentado recientemente en la XII Legislatura. En mayo de 2017 se interpone una moción de censura por 35 diputados, pertenecientes al Grupo Parlamentario Confederal de Unidos Podemos-En Comú Podem-En Marea, presentando como candidato al diputado Pablo Iglesias ${ }^{61}$. Se justifica la presentación de la misma por los firmantes aduciendo, que en su opinión el Gobierno está utilizando «la impunidad, el saqueo y la corrupción» para ejercer sus funciones públicas.

La moción fue debatida en Pleno los días 13 y 14 de junio y el resultado de la votación supuso un claro rechazo a la moción presentada pues solo obtuvo 82 votos a favor (además de los integrantes del grupo parlamentario que había presentado la moción, la apoyaron los diputados de Compromís, ERC y EH-Bildu), frente a 170 en contra (PP, Ciudadanos y Coalición Canaria) y 97 abstenciones (PSOE, PNV y PDeCAT) ${ }^{62}$.

La tercera moción de censura de la democracia terminó de manera similar a las otras dos que acabamos de analizar: con más votos en contra que a favor. La única diferencia es que en las otras dos los votos en contra superaron la mayoría absoluta, mientras que en este caso el Presidente cuenta exactamente con los mismos apoyos que tuvo en la investidura. Aunque según se refleja en la prensa de esos días esta moción fallida sólo ha servido para reforzar a Rajoy, pronto es aún para señalar consecuencias políticas de la misma.

\section{A MODO DE RECAPITULACIÓN}

A lo largo de estas páginas hemos pretendido describir el proceso de investidura que han seguido los diferentes Presidentes del Gobierno desde la I Legislatura, a la vez que también se ha hecho referencia a los dos mecanismos de exigencia de la responsabilidad política que recoge nuestra Constitución. Cierto es que investidura, cuestión de confianza y moción de censura son tres situaciones en las que se pone de manifiesto las relaciones entre el Gobierno y las Cortes Generales, y muy principalmente en el Congreso de los Diputados, ante el que el Gobierno debe responder de manera solidaria como ya hemos señalado. En cualquier caso, estudiar los problemas de inestabilidad, de ingobernabilidad o de inseguridad que un Gobierno en minoría tiene permitirían tratar muchos más aspectos que exceden a este estudio. Los problemas de un Gobierno para sacar adelante iniciativas legislativas, especialmente los Presupuestos Generales o la aprobación o modificación de cualquier Ley Orgánica, o

\footnotetext{
60 Blanco Valdés, R., op. cit., p. 76.

61 BOCG-CD, núm. 161, de 26 de mayo de 2017.

62 DSCD, núm. 61, de 14 de junio de 2017.
} 
las dudas acerca de la convalidación de un Decreto Ley son cuestiones de gran relevancia que afectan a la estabilidad y, por ello, al funcionamiento de todo el sistema.

Es importante que un Gobierno esté sujeto a frenos y de ahí la importancia del control e incluso de la exigencia de la responsabilidad política. Existe un sentimiento generalizado sobre la dudosa eficacia del control. En este punto se confunde el objetivo que tiene la función de control, que prevé el texto constitucional, con el sentido que tiene la exigencia de responsabilidad política. La primera tiene una finalidad que no produce ningún efecto a corto plazo. La segunda tiene efectos jurídicos marcados por la misma Constitución y, por lo tanto, puede afectar a la existencia y permanencia del Gobierno. Dicho en otras palabras, los efectos son de mucha más trascendencia y por ello no deben ser mecanismos que se utilicen con ligereza. Cuando el funcionamiento regular de las instituciones no es posible, es cuando se producen los conflictos y los desacuerdos.

Es evidente que nuestra Constitución intenta garantizar, con el procedimiento de investidura, por una parte, la posibilidad de que el Gobierno tenga estabilidad, exigiéndose mayoría absoluta en primera votación; pero, por otra parte, la pretensión de que los candidatos busquen apoyos en el Congreso y, en su caso, consigan acuerdos para obtener en segunda votación la mayoría simple. Si esto no es así, en aras de evitar vacíos de poder y previsiblemente conflictos, se apela al electorado disolviendo las Cámaras y convocando elecciones generales ${ }^{63}$.

Es cierto que hasta ahora las previsiones constitucionales al respecto, esto es básicamente las contenidas en el art. 99 CE, nos habían hecho acostumbrarnos a procesos de investidura en los que los candidatos propuestos obtenían apoyo parlamentario suficiente en primera votación con mayoría absoluta, o a lo más, en algunos casos, lo obtenían en una segunda votación, con mayoría simple. De esta manera, en el caso de la formación del Gobierno de España es inédita aún la propuesta de un segundo candidato, como lo era el supuesto de disolución de las Cortes, hasta que las Cámaras elegidas el 20 de diciembre de 2015 se disolvieron por Decreto del 3 de mayo de 2016, celebrándose nuevas elecciones el 26 de junio del mismo año.

Con la nueva situación que estamos viviendo «persiste, un temor a que se produzca en España un fuerte deterioro de la situación de gobernabilidad que ha caracterizado nuestro período democrático, al menos desde 1982, tras los cambios que se han producido en el sistema de partidos, un deterioro del que habrían sido un anuncio contundente los diez largos meses de interinidad política» ${ }^{64}$.

Ha señalado el Tribunal Constitucional que «el modelo parlamentario no ha de considerarse únicamente como un mero mecanismo técnico, sino que se inserta en el

63 Bar Cendón, A., El Presidente del Gobierno en España: encuadre constitucional y práctica política, Madrid, 1983, pp. 159-160. Aunque la doctrina es mayoritaria en considerar inadecuada la disolución del Senado también hay autores que defienden la disolución conjunta. Vid. los citados por REVENGA SÁnCHEZ, M., La formación del Gobierno en la Constitución española de 1978, Madrid, 1988, p. 40 y 41.

64 Blanco Valdés, R., op. cit., p. 94. 
orden de valores y principios (constitucionales), a los que sirve y que han de inspirar la interpretación de las normas que lo regulan» ${ }^{65}$.

Así, el todo nuestro sistema está presidido por la lógica consecuencia de la existencia de una relación básica que liga de forma directa e inexcusable al Gobierno con las Cortes, en concreto con el Congreso de los Diputados en el régimen parlamentario. Es fruto del principio en virtud del cual la actividad del Gobierno descansa en la confianza parlamentaria, de que precisa de una mayoría en el Congreso para existir, y, consecuentemente, está sometido a responsabilidad política ${ }^{66}$.

Generalizada es la opinión en este punto, tanto de la doctrina como del sentir ciudadano, que en la relación Gobierno-Parlamento, se ha producido un cambio notable en virtud del cual también se incorpora a la función de control la dialéctica entre mayoría y oposición. Así la mayoría aprovecha el ejercicio de la función de control para permitir el lucimiento del Gobierno y el control que ejerce la oposición queda en ocasiones vacío de contenido por ser ésta minoritaria. Esta afirmación, que como digo es reiterada en numerosas ocasiones, puede empezar a ser incierta en el momento en que el gobierno tenga un apoyo minoritario en las Cortes y sea sometido al control por una auténtica oposición ${ }^{67}$. El principio democrático debe permitir que en el ejercicio del control se garantice el debate público, así como el conocimiento de los asuntos públicos. Pendiente queda en nuestro sistema determinar el papel que debe jugar la oposición, papel probablemente esencial en el futuro ${ }^{68}$.

Muchos de estos problemas que se están generando en nuestro sistema constitucional no se solucionan con una reforma de la Constitución, como parece que se está propugnando en los últimos tiempos. Este convencimiento de que la modificación de la Constitución es el paso necesario para solucionar las crisis supone un desconocimiento real del contenido de la Constitución, lo que deslegitima ese planteamiento. Los representantes políticos no ceden frente al otro, porque su misión se ha convertido en lograr el máximo interés partidista, un trabajo que el ciudadano contempla desilusionado y, en muchas ocasiones, dolido y enfadado. Para reformar la Constitu-

65 STC 141/1990, de 20 de septiembre, F. J. 4.

66 SÁnchez De Dios, M., «La esencia del régimen: el control parlamentario del Gobierno», en Política y Sociedad, núm. 20, 1995, p. 36.

67 «Así, la minoría, a través del control, no sólo podrá velar por el interés general, del que es tan portador como la mayoría, sino que podrá poner de manifiesto sus principios programáticos para que el Gobierno-mayoría lo pueda tomar en cuenta (control-influencia), además de su virtualidad para influir en electorado. Cuando, por el contrario, los mecanismos de control se dejan en manos de la mayoría que apoya al Gobierno, el control puede distorsionarse, convirtiéndose en un instrumento que sirva para que la mayoría se «perpetúe» en el poder. En efecto, la mayoría puede utilizar el control sólo con el objetivo de brindar al Gobierno un foro público exculpatorio (lo que podría denominarse un control-publicidad), alterando las funciones naturales del control (inspección, enjuiciamiento y adopción de medidas correctoras o ratificadoras)»: FERnÁndez SARASOla, I., «El control parlamentario y su regulación en el ordenamiento español», en Revista Española de Derecho Constitucional, núm. 60, septiembre-diciembre 2000 , p. 100.

${ }^{68}$ Interesante en este punto el trabajo de Sánchez Navarro, A. J., op. cit., en especial en cuanto al concepto de oposición las pp. 29-33. 
ción es ineludible actuar con prudencia, huyendo de la precipitación, de la improvisación y de la demagogia. La reforma es una previsión para que la Constitución no quede alejada de la realidad o para que sus contenidos no sean inaplicables por caducos, pero es un presupuesto que no debe ser utilizado cuando las condiciones políticas no son las adecuadas.

El incierto papel de las minorías en las Cortes, incluso de la oposición, y la rígida disciplina de los grupos parlamentarios están modificando la forma de ejercer las funciones parlamentarias, tema especialmente relevante en un momento de impasse político. Los grupos minoritarios en las Cámaras, no han sido alternativa de gobierno, a veces ni siquiera se ha contado con ellos para establecer acuerdos. Parece que ha primado exclusivamente la matemática, de tal forma, que el objetivo del acuerdo no ha sido tanto el contenido, sino el número de votos necesario para que cualquier iniciativa fuera aprobada. La finalidad de los instrumentos de control a los que nos hemos referido es conseguir que el pueblo tenga noticia de las actividades del Gobierno, y que se adquiera acerca de esas actividades una visión crítica.

Efectivamente llegados a este momento de nuestra historia constitucional estamos pasando por un tiempo incierto. Necesitamos de un gobierno estable que pueda enfrentarse a retos importantes, retos que pueden llegar pronto y a los que hay que dar soluciones duraderas y satisfactorias en la defensa del Estado de Derecho.

Title:

Relations between Parlamient (Cortes Generales) and Government: the investiture of the President of the Government and the mechanisms of requirement for political responsibility

\section{Summary:}

I. Focus of the topic: the importance of relations between the Government and the Cortes Generales in a parliamentary system as the spanish constitution of 1978. II. The invest process of the president of the Government through different legislatures. III. About the effectiveness of the mechanisms of the requirement of political responsibility: the vote of confidence and the motion of censure. IV. To recapitulate.

\section{Resumen:}

El presente estudio se centra en las relaciones Gobierno-Cortes Generales, relaciones esenciales en un sistema parlamentario como el nuestro. Se aborda un análisis de los diferentes procedimientos de investidura que 
han seguido los Presidentes del Gobierno desde 1979 hasta la actualidad. Junto a ello se reflexiona acerca de la viabilidad de los mecanismos de exigencia de la responsabilidad política y las escasa ocasiones en las que se ha utilizado.

\section{Abstract:}

In the present study focuses on the relations Government-Cortes Generales, relations essential in a parliamentary system like ours. It analyze of the different investiture procedures that has been followed by the Presidents of the Government from 1979 to the present. In addition to this, we reflect on the viability of mechanisms for political responsibility and the few occasions in which they have been used.

\section{Palabras clave:}

Constitución, relaciones Gobierno-Cortes Generales, investidura del presidente, cuestión de confianza y moción de censura.

\section{Key words:}

Constitution, relations between the Government and the Cortes Generales, investiture of the President, the vote of confidence and the motion of censure. 